\title{
The fictive reflex: a fresh look at reflexiveness and narrative representation
}

\author{
Richard Walsh ${ }^{1}$
}

Published online: 26 October 2016

(C) The Author(s) 2016. This article is published with open access at Springerlink.com

\begin{abstract}
Reflexiveness in literary contexts tends to be assimilated to self-reference; to the various ways in which a work may foreground the artifice and conventionality of its own features as representation, narrative or language. In this sense it is equated with metafiction, and regarded as a sophisticated and highly selfconscious use of narrative; here, however, I offer a contrary view of reflexiveness, one which sees it as elementary, pervasive, and constitutive of fictionality. In this view, there is a continuity between the basic logic of mimesis and the self-conscious "baring of the device" that, for the Russian Formalists, defines the literary. I begin by clarifying the nature of (fictive) representation as an act, and identify its intrinsic reflexiveness, and go on to compare this perspective with both the metafictional notion of reflexiveness and the theoretical discourse on reflexiveness around "mirror neurons" in cognitive literary studies. I then situate reflexiveness within a broader interdisciplinary environment, framed by complex systems science and the conceptualization of emergence in terms of representational recursiveness, which allows the two sides of the discussion so far to be understood as complementary aspects of reflexiveness, one of which aligns with the cultivation of (self-) consciousness, the other with the simple enactment of systemic relations. Finally I address the conceptual challenge presented by an account of narrative, and fiction, based upon reflexiveness, and suggest some ways in which it can be understood.
\end{abstract}

Keywords Reflexiveness · Narrative · Fiction · Representation · Cognition · Emergence

In this essay I offer a view of fictionality as a narrative rhetoric continuous with the most elementary logic of narrative, via the notion of reflexiveness. I do so by

Richard Walsh

richard.walsh@york.ac.uk

1 University of York, York, UK 
drawing upon a fundamental distinction between two complementary aspects of reflexiveness, one of which aligns with the cultivation of (self-) consciousness, the other with the simple enactment of systemic relations, in order to show the interdependence between them. My starting point, however, is a recent narratological debate which crystalizes a preliminary issue concerning fictive narrative representations themselves. In the introduction to The Emergence of Mind, David Herman presents his critique of a prevalent doctrine among literary narrative theorists that he dubs the "Exceptionality Thesis": the claim, as he puts it, that "readers' experiences of fictional minds are different in kind from their experiences of the minds they encounter outside the domain of narrative fiction" (Herman 2011, 8). His own, anti-exceptionalist, stance is a claim for a certain cognitive continuity in our understanding of fictional and real other minds, though he is careful to say that he is not "suggesting that interpreters of fictional narratives adopt the same stance toward the situations portrayed in those texts that they adopt toward situations in narratives that make a claim to fact" (Herman 2011, 33, n.10). It is reasonable to question the legitimacy of Herman's discrimination between our stances towards fictional narratives and fictional minds, and indeed it has been questioned, notably from the perspective of unnatural narratology-one of the recent theoretical trends Herman explicitly associates with the Exceptionality Thesis because of its anti-mimeticism (Herman 2011, 11); I'm thinking in particular of Henrik Skov Nielsen's response in his contribution to the volume A Poetics of Unnatural Narrative (Nielsen 2013), which takes up Herman's challenge to unnatural narratology's version of exceptionalism.

I begin with this debate about the exceptionality, or otherwise, of narrative fictions, because I am struck by the extent to which both sides cast their general arguments, and their finer conceptual distinctions, in terms of the objects of representation. That is, both Herman and Nielsen (and in truth most narrative theorists of whatever stripe) contest the nature of the disputed continuities and discontinuities between fictional and non-fictional narrative on the ground of a common assumption that fictions are representations of fictional objects. The issue then becomes a matter of whether certain of these objects (fictional minds) are intelligible in the same terms as other minds in the real world, or require a different kind of interpretative attention (intrinsically, or just in certain cases). The premise of a categorical distinction between fictional and non-fictional objects is explicit even on Herman's side where the main thrust of the argument is for continuity; as when he urges that acknowledging "the ontological divide between fiction and nonfiction is consistent with hypothesizing that the same protocols for engaging with minds cut across this divide" (Herman 2011, 12).

My perspective on fictionality, however, cuts across the terms of the debate itself. ${ }^{1}$ Both sides share the assumption that fictional representations are to be distinguished in ontological terms, whereas I take the view that a representation is fundamentally an act. That is, I want to understand the word "representation," always, as less a noun than the nominalization of a verb. On this view, acts of fictive

\footnotetext{
${ }^{1}$ The premises for the following outline of my approach to fictionality are those developed in The rhetoric of fictionality (Walsh 2007).
} 
representation are real acts, discursively-and, if you like, ontologicallycontinuous with other (real, communicative, representational) acts. Within this discursive continuity, however, fictionality is a discrete rhetoric, or rhetorical set; one that is extremely pervasive, both culturally and cognitively. It follows that, far from being one pole of an absolute ontological binary, fictionality has a complex history, and indeed a prehistory. The history refers us to emerging work in diachronic narrative theory, a post-classical development in narratological research initiated by, among others, Monika Fludernik (2003). This essay concerns itself with the pre-history, or at least the theoretical parameters of that pre-history; that is, my focus is upon considerations both historically and logically prior to the cultural history of diachronic narratology.

Fictive narrative acts have a second-degree relation to informative narrative acts; that is, they are fictive by virtue of a disavowal of their direct, assertive relevance in representational terms, whether that disavowal is implicit or explicit, or is external or internal to the fictive discourse itself. All of fiction's distinctive characteristics are contingent possibilities that arise in consequence of this reflexive move; fictive representations work fictively to the extent that they work through a dissociative framing of the indicative force of the representational act. This framing is reflexive because it takes the same form as the indicative act it disavows; reflexiveness, in this sense, is representational recursiveness. This essay is marked by an extraordinary preponderance of words with a "re-" prefix, and my contention is that in all cases, beginning with representation, the "re-" is the critical feature. The "re-" prefix articulates a relation, and often a recursive relation, to something logically or temporally prior, and this is the salient feature of acts of representation. My account of fictionality situates its reflexiveness in the context of a broader reflexive logic, one that is intrinsic in representation itself and accounts both for the possibility that fictive acts may arise and for the way that fictive acts work. With respect to the ontological premises of the exceptionality debate above, it is at best a moot philosophical point whether such fictive acts can be said in some sense to generate or refer to objects of their own. The pragmatics of the interpretation of fiction do not involve fictional objects or represented objects. ${ }^{2}$

The view I am expounding here turns instead upon acts, situated in relation to temporally or conceptually prior acts, and in doing so it privileges a reflexive idea of representation grounded in repetition; partly because I want to suggest that such an approach provides a way to understand the emergence, at a cognitive level, of representational acts out of action per se, and partly because the ideas of action and repetition involve a temporal emphasis conducive to a specifically narrative take on representational acts. That is, I am interested in fictionality specifically as an epiphenomenon of the emergence of narrative; my aim is to connect the most

\footnotetext{
${ }^{2}$ Much contemporary narratology rests upon the assumption that the interpretation of fiction does involve fictional objects (including much cognitive narratology, for reasons that I think can only be attributed to the priming effect of the literary-philosophical training of many cognitive narratologists). This assumption, to the extent that it is a theoretical premise rather than an unthinking echo of the idioms of common talk about fictions, has been formalized in terms of fictional worlds, notably by Thomas Pavel (1986) and Marie-Laure Ryan (1991); and, in the more linguistic terms of narrative semantics, by Lubomír Doležel (1980).
} 
elaborate cultural manifestations of fictionality with the inaugural moves of narrative cognition. ${ }^{3}$ To offer an account of fictionality's emergence itself as a narrative, however, is rather more problematic, precisely because of the narrativeresistant logic of recursion that is a feature of the systemic relations underlying emergent phenomena. This is a limitation of narrative cognition that $\mathrm{I}$ have discussed elsewhere, and I won't belabour it here; it is simply that the sequential logic of narrative is unable to accommodate the multiplicity, simultaneity and reciprocity of interactions involved in systemic processes, even as our cognitive grasp of process is constrained by that sequential logic; and therefore the accessibility of emergent behaviours to narrative representation comes only at the cost of woeful misrepresentation of the systemic interactions actually producing that behaviour. ${ }^{4}$ This limitation upon narrative representation in general implies that there are some considerable barriers to understanding inherent in my own specific undertaking here, and if I am to make any progress at all, I need to acknowledge them. So, I have to grant immediately that there is a necessary tension between my appeal to systemic processes and the form of my argument as a narrative of (conceptual) origins. To conceive of representation as a reflexive process grounded in repetition is not really to ground it at all, because there is a circularity lurking in the formulation. Nothing ever happens twice, except under interpretation-which is to say, except as represented. Repetition is itself already reflexive.

\section{Let me begin again}

Reflexiveness in literary contexts tends to be assimilated to metafictional selfreference; that is to say, in literary criticism we think of reflexiveness in terms of the various ways in which a work may overtly foreground the artifice and conventionality of its own features as fiction, as narrative, as representation, or as language. In this sense reflexiveness is typically regarded as a sophisticated and highly selfconscious feature of narrative; whereas my purpose is to offer a contrary view, which sees reflexiveness as elementary, pervasive, and constitutive not only of fictionality itself but also of the pre-requisite possibility of narrative representation.

Metafictional reflexiveness has in the past been castigated as a decadent practice in literary-critical discourse. It is has been viewed as a malaise, a symptom of the death of the novel, the defining quality of a literature of exhaustion, in John Barth's classic formulation (1967). In the heady early days of postmodernism it was both celebrated and castigated as a scandalous exposé, or dereliction, of fiction's cultural role, provoking neo-realist backlash even as the devices of metafictionality and selfreflexive irony went mainstream and lost their antinomian aura; as Gerald Graff trenchantly noted in response to the latter development, consumer capitalism is

\footnotetext{
3 In pursuing this narrative lineage, of course, I am neglecting forms of fictionality (in the visual arts, for example) that are not contingent upon narrative.

4 A fuller exposition of the double bind entailed in the narrative representation of systemic processes can be found in Walsh (2011a). A volume of essays in preparation, Narrating complexity, directly explores the problem in dialogue between narratologists and complex systems scientists (Stepney and Walsh forthcoming).
} 
more than happy to commodify its own ironization (Graff 1979, 223-224). Even attempts to engage positively with the strategies of postmodern metafictionality have had to proceed by negotiating with its highly suspect cultural status. I might cite David Foster Wallace's heroic efforts in his own fiction to push through metafictionality to the other side of irony, the cultural pervasiveness of which had become enervating (Wallace 1993). Or we might consider the way Linda Hutcheon's influential formulation of "historiographic metafiction" vindicates metafiction's obsession with its own artifice by reading it as a demonstration of the similar, but unacknowledged, artifice of non-fictional narrative discourses (Hutcheon 1988), a view in which fiction's retort to historiography is, in effect, "you think I'm bad?" Or we might recall Brian McHale learning to "stop worrying and love postmodernism" by reading it as a formal, metafictional interrogation of ontology (albeit founded upon the sort of fictional worlds semantics I've just rejected) which nonetheless is ultimately recuperated in terms of a meta-thematics of love and death (McHale 1991, 217-232).

The most carefully formalist analysis of postmodern metafiction, however, is also the one in which its categorical distinctiveness starts to break down. This is Patricia Waugh's Metafiction, which proposes a "sliding scale of metafictional practices" (1984, 115); pursuing this classification from the moderate to the extreme, Waugh arrives at an unexpected endpoint, concluding that "all fiction is thus implicitly metafictional" $(1984,148)$. We might arrive at similar conclusions by following this sliding scale in the other direction. Once detached from the particular context of postmodernism, metafictionality of course assumes a much more integral place in the whole history of fiction. Without any redefinition of its scope, it is thereexplicitly, if sporadically-almost everywhere you look. It is strongly correlated with liminal moments in the history of narrative fictions; moments of various kinds, on various scales. So it is there at a particular narrative crux in Trollope, or in the framing of a twice-told tale by Hawthorne, or the renouncement of an out-moded convention in Diderot. The most striking outbreaks of extensive metafictionality seem to coincide with the early stages of a new genre, form, or medium of fiction. Obvious cases would be Don Quixote, or Tristram Shandy; but the same might be said, for example, about the intensely self-reflexive negotiations between illusionism and narrative in the first years of cinema. ${ }^{5}$ Metafictional reflexivity, in other words, would be a powerful lens through which to take a diachronic perspective upon generic fictionality.

But from my point of view here, metafictionality is just the most overt and performative end of a spectrum of kinds of reflexiveness; the reflexiveness that is most fundamentally, I suggest, the generative principle for fictive narrative acts in particular and for acts of narrative representation in general. I've emphasized the liminal status of metafictionality because it accords with, and epitomizes, the inaugural function of reflexiveness in a much more general sense, as a recursive series of representational moves: metafictionality is a feature of the emergence of

\footnotetext{
5 The complexity of these negotiations is apparent in Tom Gunning's "The cinema of attractions: Early film, its spectator and the avant garde" (1990), as well as in several of the other essays in the same volume.
} 
new cultural forms and genres just as the principle of reflexiveness is a feature of representation inherent in the systemic logic of emergence itself. That is to say, beyond the threshold of overt reflexiveness there is a larger continuity that extends all the way from the basic logic of mimesis to the self-conscious baring of the device that, for the Russian Formalists, defined the literary (Shklovsky 1965b, 26-30). Shklovsky famously declared Tristram Shandy "the most typical novel in world literature" (26), and I want to appropriate the remark in a sense that goes well beyond the terms of Shklovsky's own polemic. I can use the double logic of his own account of defamiliarization to partially justify the theft, however. Defamiliarization is, apparently, both the arch-principle of literariness as a ceaseless reflexive foregrounding of artifice and, at the same time, the basis upon which the value of the literary is affirmed in terms of a phenomenal aesthetics of everyday life; defamiliarization serves to prolong perception, to "make the stone stony" (Shklovsky 1965a, 12). Defamiliarization, that is, faces both ways; its selfconscious dissociation from experience is itself the condition of its orientation towards it.

My point is that mimesis and baring the device are not antagonists but accomplices; and further, that this reciprocity does not only apply at the level of literary narrative, but across the whole range of narrative representations, including the mental representations of narrative cognition. Reflexiveness is not the destruction of representation, because representation is reflexive. More than that, representation is actually constituted by reflexivity, and reflexivity intrinsically constitutes representation. The possibility of recursion, of return, of repetition, entails representation because nothing ever happens twice, except under interpretation. Repetition is itself already reflexive.

\section{Let me begin again}

When the neurological research on mirror neurons first appeared, it struck a chord with many scholars interested in the relation between literature and the way our brains work. The interest, however, had less to do with the phenomenon described in the neurological research than the term itself-with that particular way of conceptualizing the findings. The neuroscientific phenomenon was first observed and described in a 1992 paper (Di Pellegrino et al. 1992), but the term "mirror neuron" was not coined until 4 years later (Gallese et al. 1996). The mirror metaphor captured widespread attention, not least in literary-critical circles where it inevitably evoked a whole tradition in Western aesthetics, that classic trope for mimesis epitomized by Hamlet's injunction to the players at Elsinore to hold "the mirror up to nature" (III.ii). The neuroscience of mirror neurons seemed to provide an empirical foundation for a whole set of literary-theoretical ideas about representation, especially fictional representation, as well as about the nature of readers' engagement and emotional involvement with it; and, as enticingly, it offered a new scientific terminology with which to describe these things. In particular, it led to a widespread and somewhat hasty assumption that mirror neurons corroborated theories of mental simulation-an argument put forward by 
Gallese and Goldman (1998) — and that this confirmed certain theories of reader response to fictive representations (notably, fictional worlds theories).

I particularly admire Marie-Laure Ryan's response to all this in "Narratology and cognitive science: A problematic relation" (2010). The article was occasioned by one of many popularising press releases hailing the confirmation of theories of mental simulation by neuroscientific research (in this case, specifically in response to narratives, as registered in MRI scans). Ryan's own work has long advocated a fictional worlds model of readers' experiences of fictions, as well as a view of reader involvement as virtual cognitive and affective immersion in those worlds, and she acknowledged the temptation, perhaps as strong for her as for anybody, to hail this kind of neurological research as final scientific validation of her arguments. She was tempted, but she resisted; she did not fall. On further reflection her critical faculties prevailed, and she adopted a highly sceptical stance on the extent to which the empirical findings actually justified the interpretative gloss given them by the science media and by less rigorous scholars. Her reasons were several, but the one I would pick out is the way in which the interpretative gloss given to neuroscientific research has a tendency to presuppose the very things it is taken to demonstrate. This circularity is particularly evident in the transition from research papers to journalistic articles, as in the case with which Ryan begins (2010, 470-471), but it is also frequently, and more insidiously, a tendency in the conceptualization of the research itself.

The conception of mirror neurons is a case in point; the enthusiasm with which some narratologists and literary scholars have embraced the mirror metaphor disregards the extent to which its original use had already imported the connotations of that metaphor, precisely because of their cultural currency. Yet while the excitement around mirror neurons in narratological circles has naturally tended to understand the metaphor in terms of the virtual image in the mirror, that archetype of mimesis, the metaphor was originally used to characterise the action of these neurons. That is to say, a mirror neuron is one triggered when a certain action is performed and when the same action is witnessed; which suggests that if the metaphor is applicable at all, it might more plausibly be taken another way. A reflection, indeed, is not a representation in the artefactual sense in which that term is commonly understood, but the effect of a situated process of observation; there is no image in the mirror independent of the act of viewing it. A reflection is a "reflex image," in the sense most familiar from the term "single lens reflex camera," an epiphenomenal result of the turning back of light by the reflective surface of the mirror, which is only resolved into any form at all from the perspective of a specific subject position. And as a matter of fact, the scientific research on mirror neurons has a closer relation to reflexes-in the sense of automatic actions-than to images. The firing of a mirror neuron is not a mirroring in the sense of an imaging, but in the sense of a repetition, at the neurological level, of the associated action perceived in another. Ah-but even as repetition, it does not so much produce as presuppose a representational relation: nothing ever happens twice, except under interpretation. Repetition is itself already reflexive. 


\section{Let me begin again}

My title, "The Fictive Reflex," is designed to bridge the gap between "reflexiveness" in the familiar literary sense and "reflex" in the sense it has in "reflex action." Both, of course, trace their etymology back to the same source in classical Latin, reflexus, meaning bent or curved back (OED). But a reflex in the sense of a reflex action, strictly defined, is a connection between a sensory neuron and a motor neuron via a reflex arc, and so not routed via the brain or mediated by cognition; a simple feedback loop between body and environment. Reflexes are therefore involuntary actions; indeed the concept of reflex action, though not the word itself, was introduced by Descartes as part of his mechanistic account of the body, as distinct (in humans) from the attributes of reason, mind and soul (1664/1972). Reflex and reflexiveness on the Cartesian model, then, respectively mark the poles of an antithesis between, on the one hand, unconscious, automatic behaviour and, on the other, rational, conscious behaviour. Modern psychology has a more capacious view than Descartes's of what mind is, and what thinking is - a view that accommodates both the automatic and the reflective, thinking fast and slow (Kahneman 2011). But some residue of the old Cartesian dualism still remains unless we can conceive of conscious thinking as something that emerges, ontogenetically and phylogenetically, out of reflex action.

My own concern here is to emphasize the continuity, rather than antithesis, between reflex and reflexiveness, by seeing them as a complementary pair. The relation between them is between two aspects of the same formal move, that turning back on itself. Conceived as reflex, this is a move defined within the parameters of some systemic set of relations; conceived as reflexiveness it is the same move, with respect to the same set of relations, but understood now in terms of the difference inaugurated by the move itself. This difference (for that which turns back is not that upon which it returns) opens up an external, emergent perspective upon the systemic domain in which it occurs, which can be understood as the general condition for the incipience of the representational relation. On this view, reflex always produces and makes available the possibility of reflexiveness, and it is for this reason that it is a mechanism primed for emergence within any system. The mediating term here, between systemic and emergent, between act and representation, is the implicit. The implicit is a liminal space created in turning back, itself a property of behaviour at the systemic level but already latently a vehicle for emergent behaviour at a higher level. ${ }^{6}$ Recursively, at every level, reflex becomes reflexiveness; the implicit becomes explicit; what was act becomes occasion. Recursion both is and is not repetition, because nothing ever happens twice, except under interpretation. Repetition is itself already reflexive.

\footnotetext{
${ }^{6}$ The implicit, which leads on representation without itself being representation, has a proto-semiotic function analogous to the proto-communicative function of the "manifest" in the pragmatic, speech-act oriented context of Relevance Theory (Sperber and Wilson 1986).
} 


\section{Let me begin again}

I want to say that narratives in general, and fictions in particular, are representations, and mean by that not that they correlate with objects of representation but that they are acts of representation. This way of formulating the issue evidently raises a kind of grounding problem; a concern about where, if not in relation to an object, we are to place the foundations of representation. But the grounding problem was always there; if objects of representation are not themselves already representations-that would be the condition of their foundational status - then they do nothing in themselves to account for a representational relation towards them. This issue doesn't go away when we pursue the logic of narrative representation back to some notion of primary cognitive templates for narrative representation, such as the varieties of image schema Mark Turner uses as the foundations for story and parable in The Literary Mind (1996); even here the elementary cognitive figure, conceived as grounded in embodied experientiality, harbours an ambiguity: if the image schema is itself representational (and it must be to do its work), what is it a representation of, and how does that representational relation arise? It won't do to say, in effect, it's turtles all the way down, and this is where I think enactive approaches to cognition can help. My suggestion is that what is needed is the category of the implicit, which is not representation but which opens up the cognitive space for a reflexive move that inaugurates representation. There is much in the speech-act theory tradition of communicative pragmatics that lends weight to this idea, and the generalization I am proposing from communicative behaviour to representational behaviour, or representation, as such, is not a huge leap. The implicit does the required work in mediating between action and representation precisely because the implicit is inherent in behaviour at a very fundamental level; not just conscious, deliberative behaviour but all oriented or responsive behaviour as such, in the broadest biological sense-I mean in a sense that encompasses bacterial behaviour as well as human behaviour.

I am seeking to draw out the full import of the basic philosophical re-orientation involved in an approach to fiction, narrative representation, and representation as such in terms of acts; as reflexive cycles of action within an enactive account of cognition. The re-orientation involved is, I would suggest, from substance metaphysics to process metaphysics ${ }^{7}$; from the kind of intellectual stance that is driven by a methodology of analytic reduction, seeking always to identify more fundamental elements, things, stuff, to the kind of stance that, on the contrary, is always looking to synthesize more inclusive acts, events, processes. The point I want to emphasize is that process philosophy is not a way for substance philosophy to evade its problems with foundationalism; if it applies, it applies systemically. It is in the domain of systems thinking that the concept of emergence belongs, and much of what I'm reaching towards here has to do with trying to think about fictive acts, narrative acts and representational acts as themselves the emergent behaviours of systemic processes. Enactivism, in other words, does not serve to launch

\footnotetext{
7 The entry on process philosophy in The Stanford encyclopedia of philosophy helps to clarify the issues here (Seibt 2013).
} 
representationalism; rather, you might say, it's turtles all the way up. My thought here shares with recent trends in evolutionary literary studies an interest in the continuity between basic cognitive affordances and cultural phenomena in general (or in my case, fictive rhetoric in particular); but my claim is that such continuities should be conceived in terms of reflexive processes and levels of emergence in a systemic paradigm rather than in the form of narrative accounts of the more or less mediated causal relations between cognition and culture. ${ }^{8}$ But it must be acknowledged that it is hard to resist making these connections in a narrative mode of explanation, even though systemic processes, by their nature, are not amenable to it; and it is equally hard even to recognize the explanatory force of arguments that are not cast in narrative form.

One of the ways in which I have previously tried to tell such a non-story, and which may serve as a clarifying example here, concerned the possible common cognitive roots of music and narrative in pre-linguistic communicative behaviour characterized in terms of its somatic, social and affective dimensions (Walsh 2011b). The conceptual focus of this inquiry was rhythm, and it seems to me now that more could be said about the place of rhythm in our cognitive development and in the emergence of representational behaviour. Rhythm, after all, is as pure an instance of repetition as you are likely to find. For rhythm to be perceptible as such, that is to say for it to be rhythm at all, requires the persistence in a rudimentary sense of what is past; a beat, however manifest, is only a beat relative to a prior beat. ${ }^{9}$ That implicit relation, effectively constitutive of phenomenal temporality, can serve as an archetype for the way I am trying to formulate the general conditions for reflexiveness to become manifest, and for the cognitive and communicative architecture of representational, narrative and fictive behaviour, recursively, to emerge. Otherwise, after all, each separate beat or pulse is just what it is. Nothing ever happens twice, except under interpretation. Repetition is itself already reflexive.

Open Access This article is distributed under the terms of the Creative Commons Attribution 4.0 International License (http://creativecommons.org/licenses/by/4.0/), which permits unrestricted use, distribution, and reproduction in any medium, provided you give appropriate credit to the original author(s) and the source, provide a link to the Creative Commons license, and indicate if changes were made.

\section{References}

Barth, J. (1967). The literature of exhaustion. Atlantic, 220(2), 29-34.

Boyd, B. (2009). On the origin of stories: Evolution, cognition, and fiction. Cambridge: Harvard University Press.

\footnotetext{
${ }^{8}$ For an approach to evolutionary literary studies that gives a central place to narrative, see Boyd 2009.

9 This formulation has the slightly counter-intuitive implication that there is in a sense no first beat, except retrospectively; Peter Rabinowitz (in conversation) has proposed the reverse - that a beat is only a beat relative to a following beat. But that has the more serious disadvantage that every beat becomes a beat retrospectively, which conflicts with the necessary attentional focus on the present beat (the punctual nature of which is fundamental to its phenomenal quality as a beat and to the possibility of rhythmic entrainment).
} 
Descartes, R. (1972). Treatise of man (T. S. Hall, Trans.). Cambridge: Harvard University Press. (Original work published 1664).

Di Pellegrino, G., Fadiga, L., Fogassi, L., Gallese, V., \& Rizzolatti, G. (1992). Understanding motor events: A neurophysiological study. Experimental Brain Research, 91, 176-180.

Doležel, L. (1980). Truth and authenticity in narrative. Poetics Today, 1(3), 7-25.

Fludernik, M. (2003). The diachronization of narratology. Narrative, 11(3), 331-348.

Gallese, V., Fadiga, L., Fogassi, L., \& Rizzolatti, G. (1996). Action recognition in the premotor cortex. Brain, 119(2), 593-609.

Gallese, V., \& Goldman, A. (1998). Mirror neurons and the simulation theory of mindreading. Trends in Cognitive Sciences, 2, 493-501.

Graff, G. (1979). Literature against itself: Literary ideas in modern society. Chicago: University of Chicago Press.

Gunning, T. (1990). The cinema of attractions: Early film, its spectator and the avant garde. In T. Elsaesser (Ed.), Early cinema: Space, frame, narrative. London: British Film Institute.

Herman, D. (2011). Introduction. In D. Herman (Ed.), The emergence of mind: Representations of consciousness in narrative discourse in English (pp. 1-40). Lincoln: University of Nebraska Press.

Hutcheon, L. (1988). A poetics of postmodernism: History, theory, fiction. New York: Routledge.

Kahneman, D. (2011). Thinking fast and slow. New York: Farrar, Straus \& Giroux.

McHale, B. (1991). Postmodernist fiction. London: Routledge.

Nielsen, H. S. (2013). Naturalizing and unnaturalizing reading strategies: Focalization revisited. In J. Alber, H. S. Nielsen, \& B. Richardson (Eds.), A poetics of unnatural narrative (pp. 67-93). Columbus: The Ohio State University Press.

Pavel, T. (1986). Fictional worlds. Cambridge, MA: Harvard University Press.

Ryan, M.-L. (1991). Possible worlds, artificial intelligence and narrative theory. Bloomington: Indiana University Press.

Ryan, M.-L. (2010). Narratology and cognitive science: A problematic relation. Style, 44(4), 469-495.

Seibt, J. (2013). Process philosophy. In E. N. Zalta (Ed.), The Stanford encyclopedia of philosophy. Retrieved May 13, 2015 from <http://plato.stanford.edu/archives/fall2013/entries/processphilosophy/>.

Shklovsky, V. (1965a). Art as technique. In L. T. Lemon, \& M. J. Reis (Eds. \& Trans.). Russian formalist criticism: Four essays (pp. 3-24). Lincoln: University of Nebraska Press.

Shklovsky, V. (1965b). Sterne's Tristram Shandy: Stylistic commentary. In L. T. Lemon \& M. J. Reis (Eds. \& Trans.). Russian formalist criticism: Four essays (pp. 25-59). Lincoln: University of Nebraska Press.

Sperber, D., \& Wilson, D. (1986). Relevance: Communication and cognition. Cambridge, MA: Harvard University Press.

Stepney, S. \& Walsh, R. (Eds.). (Forthcoming). Narrating complexity. New York: Springer.

Turner, M. (1996). The literary mind: The origins of thought and language. Oxford: Oxford University Press.

Wallace, D. F. (1993). E unibus pluram: Television and U.S. fiction. Review of Contemporary Fiction, 13(2), 151-193.

Walsh, R. (2007). The rhetoric of fictionality: Narrative theory and the idea of fiction. Columbus: Ohio State University Press.

Walsh, R. (2011a). Emergent narrative in interactive media. Narrative, 19(1), 72-85.

Walsh, R. (2011b). The common basis of narrative and music: Somatic, social, and affective foundations. StoryWorlds: A Journal of Narrative Studies, 3, 49-71.

Waugh, P. (1984). Metafiction. London: Methuen. 